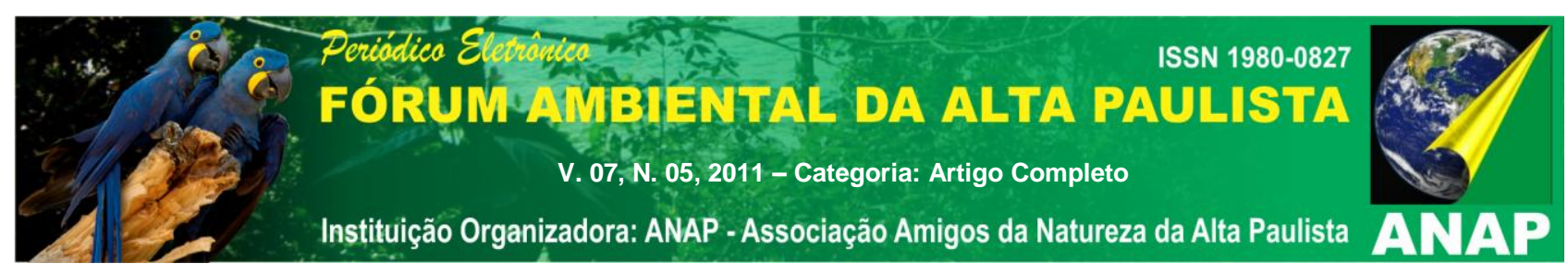

\title{
COMPENSAÇÃO AMBIENTAL EM UNIDADE DE CONSERVAÇÃO DE USO SUSTENTÁVEL
}

\author{
Roberta Leocádio Dias ${ }^{1}$
}

RESUMO: A compensação ambiental é um dos instrumentos utilizados para a consolidação dos espaços territoriais protegidos. De acordo com o art. 36, da Lei no 9.985, de 18 de julho de 2000, que instituiu o Sistema Nacional de Unidades de Conservação (SNUC), ela consiste na obrigação de o empreendedor, nos casos de licenciamento ambiental de significativo impacto ambiental, apoiar a implantação e manutenção de unidades de conservação (UC). O presente trabalho suscita o debate sobre a distinção legal contida no art. 36, da Lei no 9.985/00, que privilegia as unidades de proteção integral em detrimento das unidades de conservação de uso sustentável, as quais serão beneficiadas somente nos casos em que o empreendimento afetar diretamente esse tipo de unidade de conservação. Inicialmente aborda-se o instituto da compensação ambiental: os fundamentos legais, origem e previsão no SNUC. Em seguida, analisa-se o histórico de criação das áreas naturais protegidas no contexto mundial, abordando as correntes conservacionista e preservacionista. Por fim, comenta-se sobre a importância das unidades de conservação de uso sustentável e das populações tradicionais na conservação da biodiversidade. A partir da revisão da literatura sobre a gênese da compensação ambiental e das áreas naturais protegidas, conclui-se que a distinção de tratamento das categorias de UC's de Proteção Integral e Uso Sustentável quanto à destinação dos recursos provenientes da compensação ambiental é uma das consequências da forte influência da corrente preservacionista - que é contra a existência de populações tradicionais em áreas protegidas - no processo de construção das políticas públicas ambientais.

Palavras-chave: Compensação Ambiental. Unidade de conservação de uso sustentável.

\section{INTRODUÇÃO}

1 Advogada, Especialista em Direito Ambiental pela Universidade Federal do Mato Grosso, Analista Ambiental do Instituto Chico Mendes de Conservação da Biodiversidade. E-mail: robertaleocadiod@gmail.com 


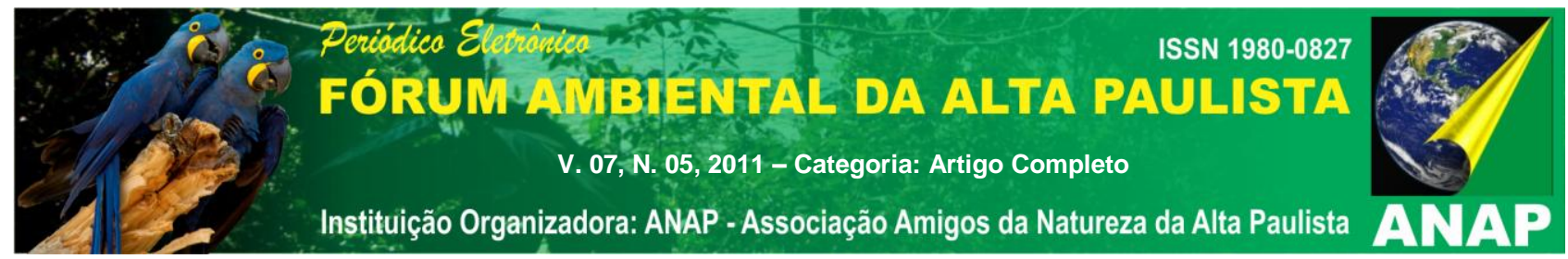

A criação de parques e reservas tem sido um dos principais elementos de estratégia para conservação da natureza, em particular nos países do Terceiro Mundo. A definição de áreas protegidas para conservação in situ das diferentes formas de vida foi, inclusive, recomendada pela Convenção sobre Diversidade Biológica às partes signatárias, como é o caso do Brasil. Entretanto, a falta de recursos financeiros é o principal obstáculo para a criação e manutenção dessas áreas.

Em nosso país, a compensação ambiental foi um dos instrumentos utilizados para ajudar na consolidação desses espaços territoriais protegidos. De acordo com o art. 36, da Lei $n^{\circ}$ 9.985, de 18 de julho de 2000, que instituiu o Sistema Nacional de Unidades de Conservação (SNUC), ela consiste na obrigação de o empreendedor, nos casos de licenciamento ambiental de significativo impacto ambiental, apoiar a implantação e manutenção de unidades de conservação (UCs).

Ao analisar o artigo acima mencionado sob o ponto de vista do gestor de uma unidade de conservação de uso sustentável, constata-se a existência de um tratamento diferenciado quanto às categorias de unidades de conservação beneficiárias da compensação ambiental. O art. 36, caput, da Lei $n^{0} 9.985 / 00$, estipulou, como regra, que o empreendedor é obrigado a apoiar a implantação e manutenção de unidade de conservação do Grupo Proteção Integral. A título de exceção, o legislador previu que, caso o empreendimento afete unidade de conservação específica ou sua zona de amortecimento, esta deverá ser uma das beneficiárias da compensação, mesmo que não pertencente ao Grupo Proteção Integral (art. 36, §3ํ, da Lei no 9.985/00).

Nesse sentido, o trabalho proposto pretende suscitar o debate sobre a distinção legal feita pela Lei no 9.985/00, que privilegia as unidades de proteção integral em detrimento das unidades de conservação de uso sustentável, as quais serão beneficiadas somente nos casos em que o empreendimento afetar diretamente esse tipo de unidade de conservação.

Apesar de a questão abordada ainda ser pouco debatida pelos estudiosos, a repercussão dessa norma é sentida no dia-a-dia dos órgãos executores das políticas públicas ambientais, já que o tratamento desigual, conferido pelo ordenamento jurídico, exclui as unidades de conservação de uso sustentável e as populações nelas existentes, 


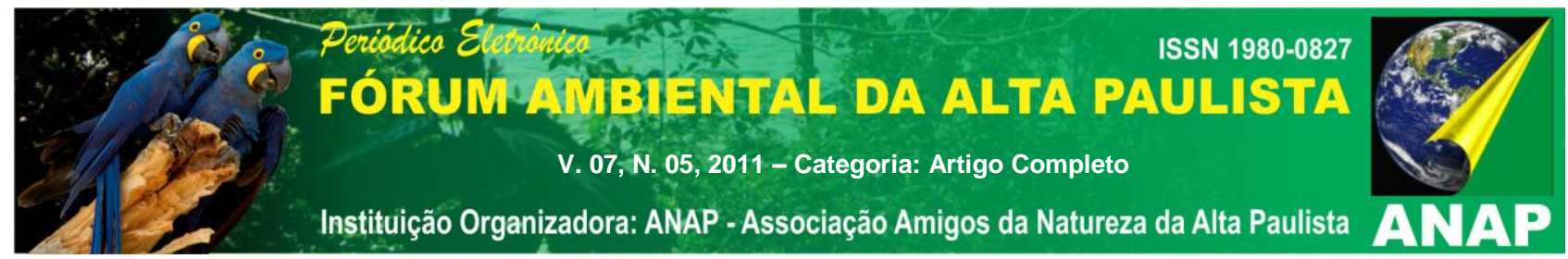

impedindo que muitos recursos provenientes da compensação ambiental sejam direcionados para a criação ou gestão desse tipo de unidade de conservação. Tal preceito, da forma como foi posto, contraria a finalidade do instituto, que é dar suporte à consolidação do Sistema Nacional de Unidades de Conservação como um todo.

\section{COMPENSAÇÃO AMBIENTAL}

\subsection{Fundamentos legais}

A Política Nacional do Meio Ambiente, instituída pela Lei n 6.938, de 31 de agosto de 1981 (art. $2^{\circ}$, inciso I) e a Constituição da República Federativa do Brasil de 1988 (art. 225, caput) erigiram o meio ambiente à condição de bem de domínio universal patrimônio da coletividade, essencial à sadia qualidade de vida, competindo ao poder público proteger esse bem e combater a poluição em qualquer de suas formas, além de preservar as florestas, a fauna e a flora.

Nesse sentido, a Política Nacional de Meio Ambiente previu que as atividades utilizadoras de recursos ambientais considerados efetiva e potencialmente poluidoras e capazes de causar degradação ambiental devem ser controladas pelos órgãos ambientais, dependendo, assim, de prévio licenciamento (art. 9º, inciso IV e art. 10, da Lei $6.938 / 81)$.

Além desse instrumento extremamente importante para a manutenção da qualidade ambiental, a Política Nacional de Meio Ambiente definiu como um dos seus objetivos a imposição ao poluidor e ao predador de recuperar e/ou indenizar os danos causados ao meio ambiente (art. 4ํㅜㅇ inciso VII, da Lei 6.938/81).

Seguindo esse princípio do poluidor-pagador, a Lei nº 9.985, de 18 de julho de 2000, que instituiu o Sistema Nacional de Unidades de Conservação, trouxe em seu bojo a figura da compensação ambiental, por meio da qual se estipulou que o empreendedor, nos casos de licenciamento ambiental de empreendimentos de significativo impacto ambiental, é obrigado a apoiar a implantação e manutenção de unidade de conservação do Grupo Proteção Integral (art. 36, caput, da Lei no 9.985/00). Estipulou-se também que se o empreendimento afetar unidade de conservação específica ou sua zona de 


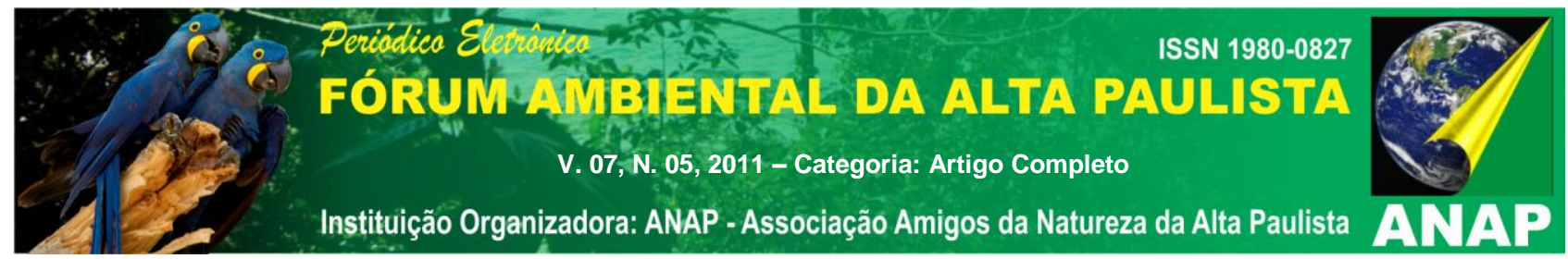

amortecimento, esta deverá ser uma das beneficiárias da compensação, mesmo que não pertencente ao Grupo Proteção Integral (art. 36, § 3ํㅡㄹ da Lei nº 9.985/00).

\subsection{Origem histórica}

Em um retrospecto sobre a gênese da compensação ambiental, FARIA (2008, p. 9), em consultoria prestada ao Senado Federal, destaca que o mecanismo da Compensação Ambiental tem uma origem histórica associada principalmente aos grandes projetos do setor elétrico brasileiro, em especial àqueles situados na Amazônia. Segundo o autor, a compensação ambiental surge a partir de um intenso processo de discussão entre técnicos daquele setor e membros da comunidade científica como uma forma de criação de áreas voltadas à conservação da biodiversidade das áreas afetadas pelos empreendimentos, servindo, assim, de testemunho das características do ambiente original.

Por uma questão de rigor histórico, FARIA (2008, p.9) destaca que a origem do mecanismo representado pela Compensação Ambiental deve ser identificada nas ideias do Prof. Dr. Paulo Nogueira Neto. Como pioneiro nas causas ambientais no Brasil, ele foi responsável pela criação e estruturação da Secretaria Especial de Meio Ambiente (SEMA), primeiro órgão ambiental no âmbito federal efetivamente estruturado. Sob seu comando (1974 a 1986), a SEMA criou dezenas de Unidades Conservação, totalizando mais de três milhões de hectares.

O autor registra que, sob a inspiração do professor Nogueira Neto, o mecanismo da Compensação Ambiental ganhou as primeiras formas na gestão do Ministro Aureliano Chaves no MME, durante o Governo Sarney. Nesse contexto, a autorização para construção de uma hidrelétrica, que já exigia a compensação financeira para todos os proprietários de terras na região afetada, passou a demandar compensação também para os ecossistemas afetados pelo projeto. Esse conceito foi ampliado, por sugestão do próprio Ministro, para empreendimentos com potenciais impactos negativos sobre a natureza.

Inicialmente, a reparação dos danos ambientais causados pela destruição de florestas e outros ecossistemas por obras de grande porte foi prevista pela Resolução 


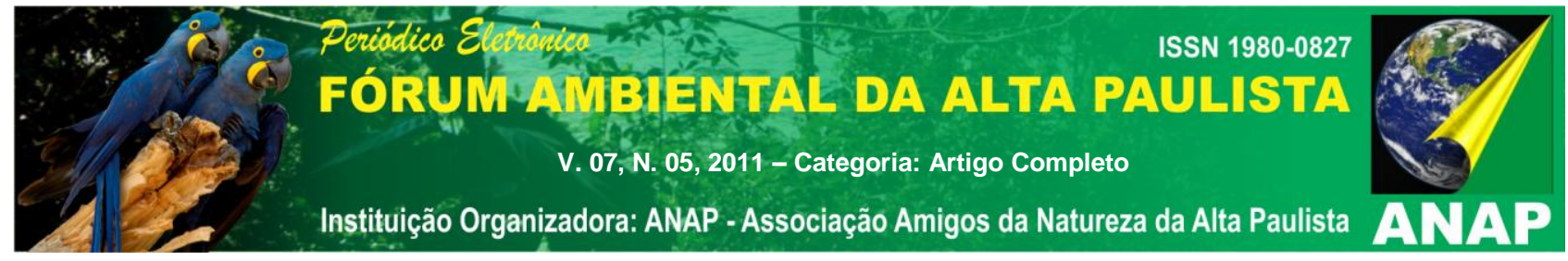

CONAMA $\mathrm{n}^{\circ}$ 10, de 03 de dezembro de 1987. A referida norma estabeleceu como prérequisito para o licenciamento ambiental do empreendimento a implantação de uma Estação Ecológica preferencialmente junto à área afetada.

Em 1996, a Resolução nํ 10 foi revogada, entrando em vigor a Resolução CONAMA n 02 , que ampliou o rol de unidades de conservação que poderiam ser implantadas em razão de empreendimento de relevante impacto ambiental. Da exclusividade de criação do tipo Estação Ecológica, passou-se a permitir a criação de qualquer modalidade de unidade de conservação de domínio público de uso indireto, ressaltando-se apenas o caráter preferencial em relação ao tipo Estação Ecológica.

Com relação à categoria de UC contemplada pelo artigo, PINTO (2005, p.300) argumenta que,

"estabelece a referida norma a obrigação dos projetos de corroborar com a implantação de unidades de conservação de uso indireto. A norma então estabeleceu uma atitude "preservacionista", como medida compensatória de uma ação "desenvolvimentista".

A partir do contexto histórico acima apresentado, verifica-se que o instituto da compensação ambiental sofreu forte influência da corrente preservacionista desde a sua origem, já que as áreas criadas para a conservação da biodiversidade objetivavam manter, de forma intacta, os ecossistemas, ou seja, não poderia haver população no interior dessas áreas, nem utilização dos recursos naturais existentes por parte dessa população.

\subsection{Compensação ambiental na Lei n 9.985/00 (SNUC)}

A Constituição Federal de 1988 (art. 225, $§ 1^{\circ}$, III) estabeleceu a definição de espaços territoriais e seus componentes a serem especialmente protegidos como uma das formas de assegurar o direito ao meio ambiente ecologicamente equilibrado.

Nesse sentido, a Lei no 9.985/00 instituiu o Sistema Nacional de Unidades de Conservação que possui como alguns de seus objetivos: contribuir para a manutenção da diversidade biológica; proteger as espécies ameaçadas de extinção; promover o desenvolvimento sustentável; proteger e recuperar recursos hídricos e edáficos; proteger 


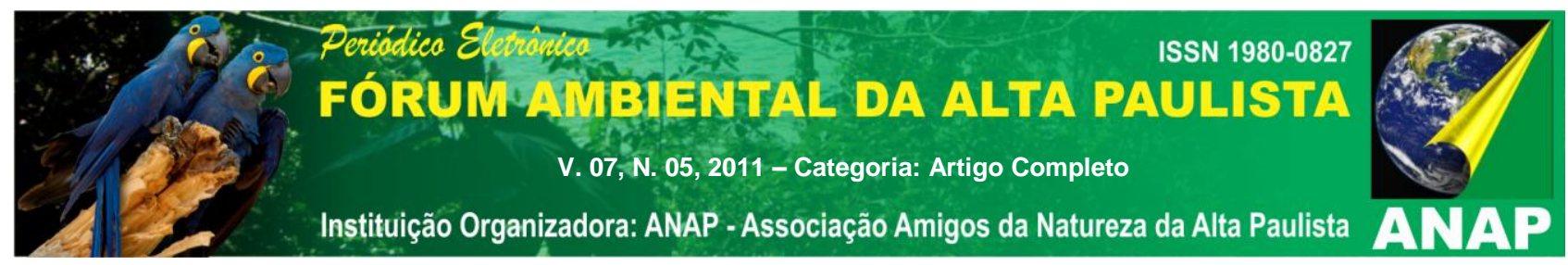

os recursos naturais necessários à subsistência de populações tradicionais.

Esse sistema é composto por dois grupos de UCs: UCs de Proteção Integral e UCs de Uso Sustentável. Nesse primeiro grupo enquadram-se: Estação Ecológica, Reserva Biológica, Parque Nacional, Monumento Natural e Refúgio da Vida Silvestre. No segundo grupo estão: Área de Proteção Ambiental, Área de Relevante Interesse Ecológico, Floresta Nacional; Reserva Extrativista, Reserva de Fauna, Reserva de Desenvolvimento Sustentável e Reserva Particular do Patrimônio Natural.

Para auxiliar na consolidação da Política Nacional de Biodiversidade, cujo substrato estrutural materializa-se na criação e manutenção de unidades de conservação - como destaca MILARÉ e ARTIGAS (2006, p. 106), a Lei do SNUC, resgatou a figura da compensação ambiental. Por meio dela, os empreendimentos causadores de significativo impacto ambiental são compelidos a apoiar a implantação e manutenção de UCs.

O art. 36, caput, da Lei n 9.985/00, estipulou, como regra, que o empreendedor é obrigado a apoiar a implantação e manutenção de unidade de conservação do Grupo Proteção Integral. A título de exceção, o legislador previu que, caso o empreendimento afete unidade de conservação específica ou sua zona de amortecimento, esta deverá ser uma das beneficiárias da compensação, mesmo que não pertencente ao Grupo Proteção Integral (art. 36, §3º, da Lei no 9.985/00).

Segundo MACHADO (2006, p. 794), o caput do art. 36 e o §3ำ registram dois tipos de incidências territoriais dos empreendimentos e dois tipos de destinatários da compensação ambiental. No caput do art. 36 os efeitos do empreendimento não irão afetar diretamente uma Unidade de Conservação específica ou sua zona de

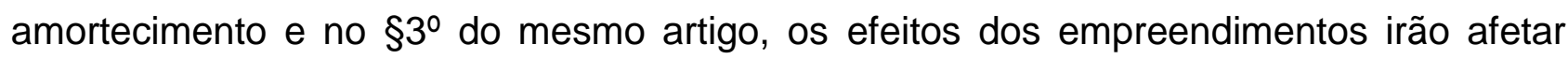
Unidade de Conservação específica ou sua zona de amortecimento. Em função disso, as Unidades de Conservação destinatárias da compensação podem ser diferentes, conforme seja o caso do caput do art. 36 ou o caso do $3^{\circ}$ do mesmo artigo.

"Se for aplicado o caput do art. 36 somente poderão receber a compensação ambiental as "Unidades de Proteção Integral", assim classificadas: Estação Ecológica; Reserva Biológica; Parque Nacional; Monumento Natural; e Refúgio de Vida Silvestre.

Ocorrendo a hipótese do $\S 3^{\circ}$ do art. 36, a Unidade afetada, mesmo não pertencente ao Grupo de Proteção Integral, deverá ser uma das beneficiárias da compensação. Nesse caso, estariam abrangidas as Unidades de Uso 


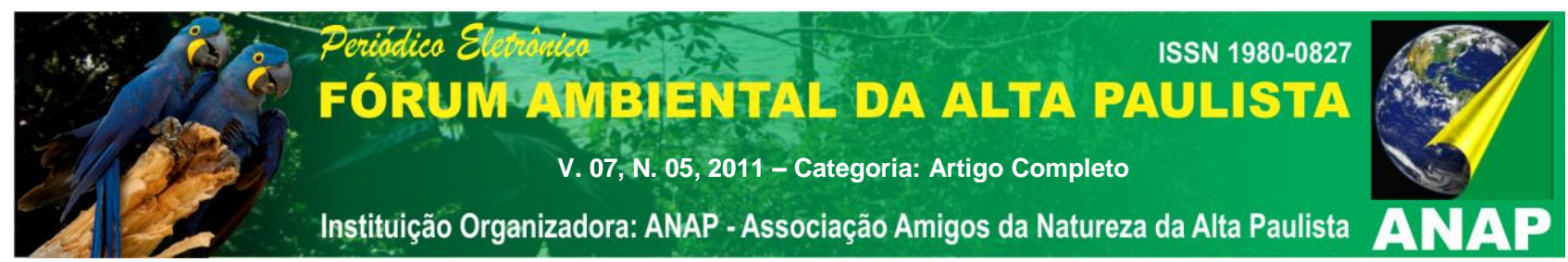

Sustentável: Área de Proteção Ambiental; Área de Relevante Interesse Ecológico; Floresta Nacional; Reserva Extrativista; Reserva de Fauna; Reserva de Desenvolvimento Sustentável e Reserva Particular do Patrimônio Natural."

A reflexão de Machado evidencia a existência de um tratamento legal diferenciado quanto às categorias de unidades de conservação beneficiárias da compensação ambiental. O caput, do art. 36, da Lei no 9.985/00, estipulou, como regra, que o empreendedor é obrigado a apoiar a implantação e manutenção de unidade de conservação do Grupo Proteção Integral. A título de exceção, o legislador previu que, se o empreendimento afetar unidade de conservação específica ou sua zona de amortecimento, esta deverá ser uma das beneficiárias da compensação, mesmo que não pertencente ao Grupo Proteção Integral (art. 36, §3ํ, da Lei no 9.985/00).

Em relação à distinção legal, salienta PINTO (2005, 301):

\begin{abstract}
"A preferência do legislador a esse grupo está exatamente na maior rigorosidade do regime jurídico dessas categorias, que somente admitem o uso indireto dos seus recursos naturais e propõe a manutenção dos ecossistemas livres de modificações advindas de ações humanas. Assim foi selecionado esse grupo para contrabalançar as perdas de biodiversidade na área de influência do projeto, sobretudo na direta.

Porém, vale atentar-se que a destinação dos recursos não é exclusiva a esse grupo, pois se o empreendimento afetar diretamente uma unidade de conservação ou sua zona de amortecimento, mesmo que se trate de uma categoria do grupo de uso sustentável, deverão essas unidades ser beneficiadas (art. 36, §3ํ da Lei do SNUC).

Entrementes, as propostas de criação de Unidades de Conservação Ambiental devem ser restritas às categorias do grupo proteção integral."
\end{abstract}

Os ensinamentos acima apresentados permitem concluir que o legislador privilegiou as unidades de proteção integral em detrimento das unidades de conservação de uso sustentável, as quais serão beneficiadas somente nos casos em que o empreendimento afetar diretamente esse tipo de unidade de conservação. Mais uma vez depara-se aqui com a influência da corrente preservacionista na história da legislação ambiental, uma vez que jamais será criada uma UC de uso sustentável com recursos da compensação ambiental. Será possível, apenas, auxiliar na implementação, se ela for, de fato, afetada pelo empreendimento. 


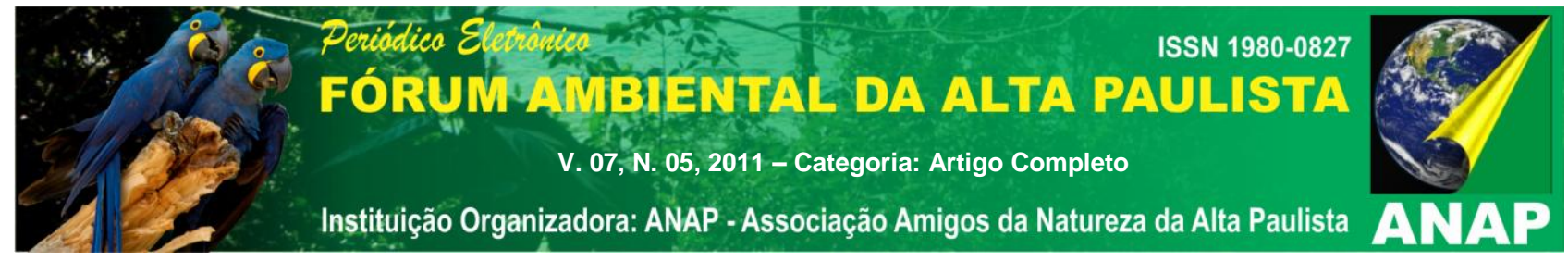

\subsection{Conservacionismo x Preservacionismo}

Conforme narra DIEGUES (2008, P. 27), o crescimento econômico que marcou os Estados Unidos no século XIX transformou radicalmente o espaço nacional. Por volta de 1890, os custos ambientais e sociais tornaram-se evidentes. A situação era tão grave que o Census Bureau, em seu famoso relatório de 1890, declarou que as fronteiras para novas expansões agrícolas estavam fechadas e que a maioria das terras devolutas governamentais haviam sido apropriadas. Tal cenário ocasionou uma preocupação crescente com a proteção ambiental.

Nesse contexto marcado por tensão e dúvidas, surgiram duas visões de conservação do "mundo natural", que foram sintetizadas nas propostas de Gifford Pinchot e John Muir.

Gifford Pinchot, engenheiro florestal (primeiro chefe do United States Forest Service), criou o movimento de conservação dos recursos, apregoando o seu uso racional. Ele acreditava que a conservação deveria basear-se em três princípios: o uso dos recursos naturais pela geração presente; a prevenção de desperdício; e o uso dos recursos naturais para benefício da maioria dos cidadãos. O conservacionismo de Pinchot foi um dos primeiros movimentos teórico-práticos contra o "desenvolvimento a qualquer custo". Essas ideias foram precursoras do que hoje se chama "desenvolvimento sustentável", tornando-se importantes na década de 70, na Conferência de Estocolmo sobre o Meio Ambiente Humano (1972), na Eco-92, além de serem amplamente discutidas em publicações internacionais como a Estratégia Mundial para a Conservação, da IUCN/WWF (1980) e em Nosso Futuro Comum (1986).

Em sentido oposto surgiu a corrente preservacionista que pode ser descrita como a reverência à natureza no sentido da apreciação estética e espiritual da vida selvagem (wilderness). Ela pretende proteger a natureza contra o desenvolvimento moderno, industrial e urbano. O preservacionismo norte-americano foi muito influenciado pelos escritos e pela obra de Henry David Thoureau que se baseavam na existência de um Ser Universal, transcendente no interior da Natureza. Outro autor importante para o preservacionismo foi Marsh, que escreveu "Man and Nature or Physical Geography as Modified by Humam Action" (1864), analisando pela primeira vez nos Estados Unidos, os 


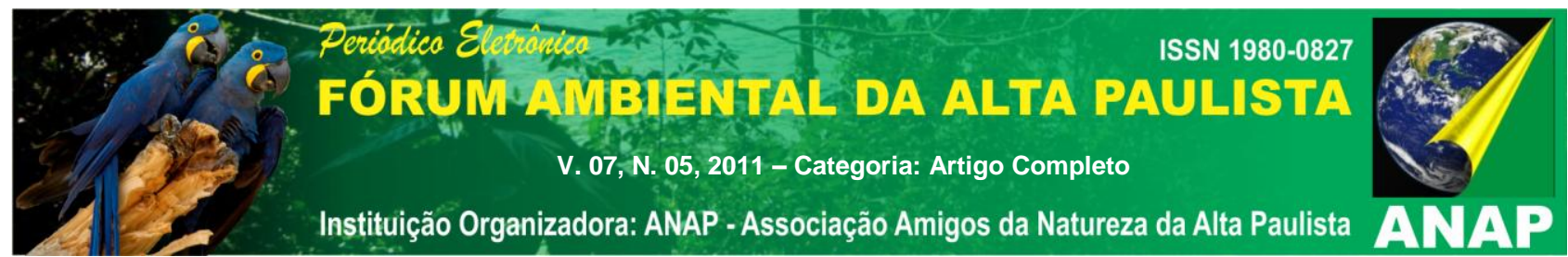

impactos negativos da civilização sobre o meio ambiente. Marsh afirma que o homem se esqueceu de que a terra lhe foi concedida para usufruto e não para consumo ou degradação.

A visão preservacionista continuou no início do século $X X$ com os trabalhos de Aldo Leopold, nascido em 1887. Graduado em Ciências Florestais, tornou-se administrador de parques nacionais no ano de 1909. Em 1949 escreveu "A Sand County Almanac", que se tornou um dos livros mais importantes para os preservacionistas.

Nos anos 50, os trabalhos de Krutch retomaram os aspectos éticos do preservacionismo americano. Segundo esse antropólogo, a vida selvagem e a ideia de vida selvagem é uma das moradas do espírito humano. Ele considerava que a modificação da natureza era benéfica até o ponto em que não interferisse drasticamente com o ecossistema como um todo. Tudo na natureza tem seus limites, incluindo o progresso humano.

\subsection{A origem da ideia dos Parques Nacionais e o surgimento da preocupação com as comunidades locais}

A noção de área natural protegida surgiu com a criação do primeiro Parque Nacional do mundo, o Yellowstone, em 1872, nos Estados Unidos. A iniciativa ocorreu durante uma expedição exploratória de colonização à região do rio de mesmo nome. Motivados pela beleza cênica do local e considerando que inúmeros outros locais com características semelhantes haviam sucumbido ao processo exploratório corrente, os pioneiros julgaram justo preservar a área para que as gerações futuras também pudessem desfrutar de tais maravilhas. Em 1ำ de março de 1872 o Congresso Americano aprovou o ato de criação do Parque, proibindo qualquer exploração que alterasse as características naturais da área, destinando-o para a preservação, lazer e benefício das gerações futuras.

Outros países aderiram ao procedimento e iniciaram a criação de Parques e outras áreas protegidas: Canadá, em 1885; Nova Zelândia, em 1894; Austrália, África do Sul e México, em 1898; Argentina, em 1903; Chile, em 1926; Equador, em 1934 e Venezuela e Brasil, em 1937. 


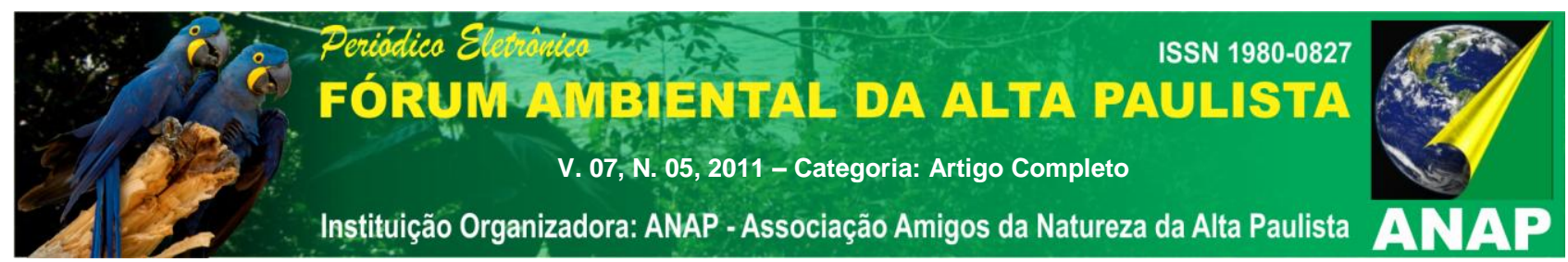

Como não havia critérios padronizados para seleção e manejo de áreas, a ideia de parque tomou características específicas em cada país. Para definir um conceito universal, realizou-se, em 1933, em Londres, a Convenção para a Preservação da Flora e da Fauna. Nela estabeleceu-se um conceito básico para parque nacional, definindo-se três características: a) são áreas controladas pelo poder público; b) para a preservação da fauna e flora, objetos de interesse estético, geológico, arqueológico, onde a caça é proibida; c) e que devem servir à visitação pública. Os conceitos de Reserva Nacional, Monumento Natural e Reserva Silvestre foram estabelecidos em outra convenção semelhante, em 1940, em Washington.

Em 1962, em Seatle, nos Estados Unidos, realizou-se a 1ํㅡㄹ Conferência Mundial sobre Parques Nacionais. Nela foram discutidos e aprofundados conceitos e critérios para atividades desenvolvidas em áreas protegidas e estabelecidas recomendações sobre políticas conservacionistas.

A $2^{\text {a }}$ Conferência Mundial sobre Parques Nacionais ocorreu em 1972, em Yellowstone. $\mathrm{Na}$ ocasião, destacou-se a necessidade de ampliação do número de áreas protegidas no mundo, incluindo-se ecossistemas marinhos, insulares, polares e florestas tropicais.

O $3^{\circ}$ Congresso Mundial de Parques Nacionais, realizado em 1982, em Bali (Indonésia), enfatizou que as áreas naturais protegidas representavam uma contribuição indispensável à conservação dos elementos vivos e ao desenvolvimento. Estabeleceu-se que a estratégia de parques nacionais e unidades de conservação somente ganharia sentido com redução do consumismo nos países industrializados e com elevação da qualidade de vida da população humana dos países em via de desenvolvimento, sem o que ela seria forçada a superexplorar os recursos naturais.

Conforme destaca DIEGUES (2004, p. 100):

"Começou a aparecer nesse Terceiro Congresso, de forma mais clara, a relação entre populações locais e as unidades de conservação. A degradação de muitos parques nacionais no Terceiro Mundo era tida como resultado da pobreza crescente das populações locais. O Congresso de Bali reafirmou os direitos das sociedades tradicionais à determinação social, econômica, cultural e espiritual; recomendou que os responsáveis pelo planejamento e manejo das áreas protegidas investigassem e utilizassem as habilidades tradicionais das comunidades afetadas pelas medidas conservacionistas, e que fossem tomadas decisões de manejo conjuntas entre as sociedades que tradicionalmente 


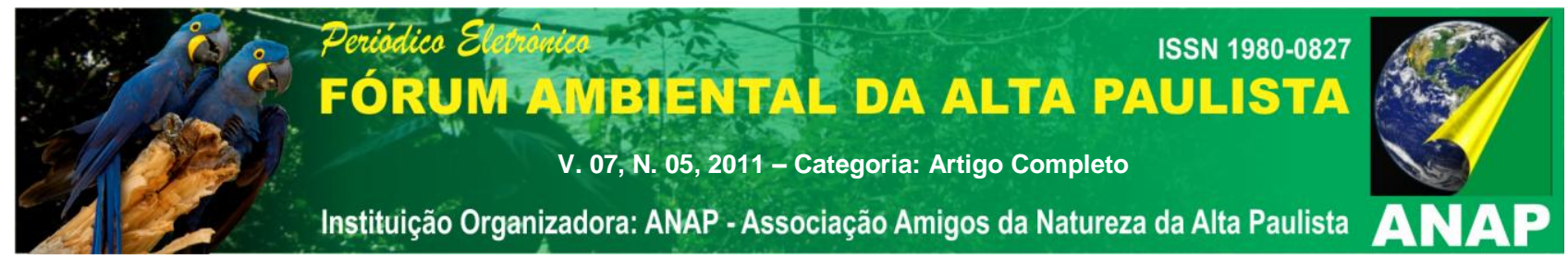

manejavam os recursos naturais e as autoridades das áreas protegidas, considerando a variedade de circunstâncias locais."

Apesar do avanço, afirma o autor que em nenhum momento se reconheceu explicitamente a existência de populações locais dentro dos parques nacionais dos países de Terceiro Mundo e nem dos conflitos gerados com a expulsão dessas pessoas.

Em 1985, o debate sobre populações em parques já ganhava destaque. Nesse ano, um número inteiro da conceituada revista Cultural Survival (vol.9, $\mathrm{n}^{\circ}$ 1, fevereiro de 1985) foi dedicada ao tema "Parks and People". O editor da revista, Jason W. Clay, iniciou a série de artigos criticando a expulsão das populações tradicionais, indígenas ou outras, das unidades de conservação, expondo que as áreas protegidas poderiam garantir a sobrevivência dos habitats e também das populações nativas e que as reservas poderiam preservar os modos de vida tradicionais ou diminuir o ritmo das mudanças a níveis mais aceitáveis e controlados pelos moradores locais.

Nessa mesma revista, publicaram-se as atas da Primeira Conferência sobre Parques Culturais, realizada em setembro de 1984, destacando-se que os valores dos modos de vida tradicionais devem ser reconhecidos e os associados com parques e reservas devem ser igualmente protegidos. Recomenda-se envolver os residentes tradicionais nas fases de planejamento e administração de parques e reservas, bem como assegurar a essas populações acesso aos recursos naturais das áreas em que vivem. Finalmente, afirma-se que a diversidade biológica e a da cultura devem ser igualmente protegidas.

O 4ํㅡㄹ Congresso Mundial de Parques Nacionais e Áreas Protegidas, realizado em 1992, em Caracas, intitulado "Povos e Parques", refletiu uma nítida mudança em relação ao tratamento que se dava às populações residentes em áreas protegidas. Essa preocupação foi reforçada por um dado publicado pela União Internacional para a Conservação (UICN), em que se constatou que 86\% dos parques da América do Sul têm populações permanentes. O workshop mais concorrido foi o "Populações e Áreas Protegidas". Um fenômeno interessante é que havia nessa reunião uma representatividade de países, sobretudo do Terceiro Mundo, muito maior que nos outros workshops. Essa reunião recomendou maior respeito pelas populações tradicionais; a rejeição da estratégia de reassentamento em outras áreas e, sempre que possível, sua inserção na área de parque a ser criada. 


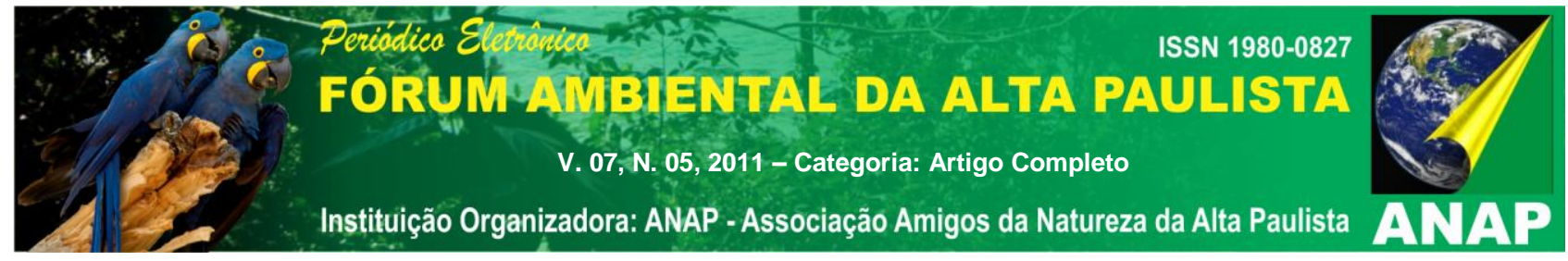

Em 2003, no 5ํㅡㄹ Congresso Mundial de Parques, realizado em Durban, na África do Sul, formalizou-se um acordo fundamentado em dois pilares: áreas protegidas e populações tradicionais. Nele foram previstas nove linhas de ação: 1- apoio significativo ao desenvolvimento sustentável; 2- apoio significativo à conservação da biodiversidade; 3- estabelecimento de um sistema global de áreas protegidas conectado às paisagens circundantes; 4- aumento da efetividade do manejo das áreas protegidas; 5fortalecimento dos povos indígenas e comunidades locais; 6- aumento significativo do apoio de outras parcelas da sociedade.

Segundo BENSUSAN (2006, p. 16), esse acordo forneceu as bases para o Programa de Trabalho sobre Áreas Protegidas, adotado em 2004 pela Convenção sobre Diversidade Biológica.

A partir desse retrospecto, MILANO $(2001$, p.9) reflete sobre o início da criação das primeiras áreas protegidas e a evolução do seu conceito, ponderando que as preocupações com a conservação da natureza evoluíram, transcendendo o conceito original, um tanto emocional, de área silvestre. $O$ autor acrescenta que, além de preservar belezas cênicas e bucólicos ambientes históricos para as gerações futuras, as áreas protegidas assumiram outros objetivos como: a proteção de recursos hídricos; manejo de recursos naturais; desenvolvimento de pesquisas científicas; manutenção do equilíbrio climático e ecológico; preservação de recursos genéticos; e preservação in situ da biodiversidade como um todo.

\section{UNIDADES DE CONSERVAÇÃO DE USO SUSTENTÁVEL E A IMPORTÂNCIA DAS POPULAÇÕES TRADICIONAIS NA PROTEÇÃO DA BIODIVERSIDADE}

\subsection{Conflito entre espaço público e espaço comunitário}

Como revela DIEGUES (2008, p. 67), a criação de áreas naturais protegidas em territórios ocupados por sociedades pré-industriais ou tradicionais é vista por essas populações como uma usurpação de seus direitos sagrados à terra onde viveram seus antepassados. O autor ressalta que essa usurpação é ainda mais grave quando a "operacionalização de um neomito" (áreas naturais protegidas sem população) se faz com a justificativa da necessidade de criação de espaços públicos, em benefício da "nação", 


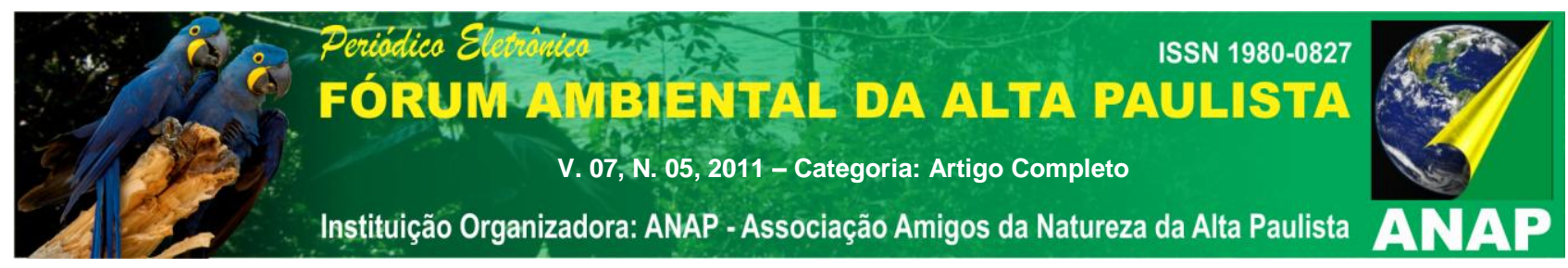

na verdade, das populações urbano-industriais.

Existe, nesse caso, um conflito entre espaço público e espaço comunitário: de um lado o Estado, representando interesses das populações urbano-industriais, e do outro as sociedades tradicionais. Para DIEGUES (2008, p. 68), o que está implícito é que a estas deveriam "sacrificar-se" para dotar as populações urbano-industriais de espaços naturais, de lazer e "contato com a natureza selvagem". Ou ainda, segundo uma versão mais moderna dos objetivos das áreas naturais protegidas de uso restrito - proteger a biodiversidade.

Esse modelo de unidades de conservação de uso restrito, segundo ARRUDA (2. ed. p. 279), baseia-se em três premissas: na dicotomia conflitante entre ser humano e natureza; na incapacidade das comunidades locais de desenvolver um manejo mais sábio dos recursos naturais e na perpetuidade destas áreas num estado de natural equilíbrio. Afirma o autor que, embora ele possa ser relativamente adequado aos Estados Unidos da América, dada a existência de grandes áreas desabitadas, sua transposição para o terceiro mundo mostra-se problemática, pois mesmo as áreas consideradas isoladas abrigam selvagens ou abrigam populações humanas.

Como consequências indesejáveis da aplicação desse modelo nos países de terceiro mundo, destacam-se: agravamento das condições de vida em muitas comunidades humanas; expulsão as populações tradicionais para as periferias das cidades, engrossando as multidões em situação de miséria e a proliferação de favelas; elevação do nível de destruição florestal, à medida que a população expulsa passa a ocupar e derrubar novas áreas para moradia; crescimento do conflito rural.

Diante desse contexto, ARRUDA (2. ed. p. 283) faz diversas indagações:

\footnotetext{
"Será que podemos imputar a responsabilidade dos conflitos e da dilapidação dos recursos naturais, como costuma ocorrer, inteiramente a pretensas características destrutivas do ser humano? Não é paradoxal que as populações tradicionais sejam postas como antagônicas às necessidades de proteção dos recursos naturais em áreas e conservação? Normalmente não são estas as populações humanas que têm há décadas, às vezes séculos e até milênios, promovido o manejo sustentável de áreas naturais? Não é a sua presença permanente que tem preservado tais áreas do modelo de exploração econômica capitalista industrial responsável pela destruição crescente do meio ambiente? Enfim, não são elas as responsáveis até o presente pela conservação das áreas que até agora tentamos pôr sob nossa proteção legal?"
} 


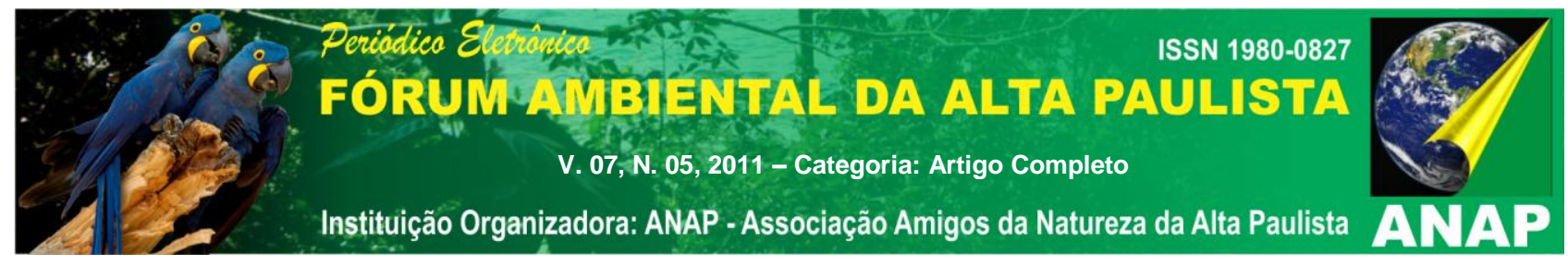

\subsection{O ecologismo dos movimentos sociais ou socioambientalismo}

A insatisfação com o modelo de desenvolvimento econômico e a consequente destruição da floresta amazônica deu origem ao chamado ecologismo social. Esse movimento, é caracterizado pela luta para manutenção do acesso aos recursos naturais, valorização do extrativismo e dos sistemas de produção baseados em tecnologias alternativas.

O socioambientalismo brasileiro, segundo SANTILLI (2010, p. 01), nasceu na segunda metade dos anos 80 , a partir de articulações políticas entre os movimentos sociais e o movimento ambientalista. Seu surgimento identifica-se com o processo histórico de redemocratização do país, iniciado com o fim do regime militar, em 1984, e consolidado com a promulgação da nova Constituição, em 1988, e a realização de eleições presidenciais diretas, em 1989. Na Amazônia brasileira, a articulação entre povos indígenas e populações tradicionais, com o apoio de aliados nacionais e internacionais, levou ao surgimento da "Aliança dos Povos da Floresta": um dos marcos do socioambientalismo.

Nesse contexto de degradação ambiental e cultural, o socioambientalismo propõe, como uma de suas ideias, a inclusão e envolvimento das comunidades tradicionais, detentoras de conhecimentos e de práticas de manejo ambiental, nas políticas públicas ambientais. SATILLI $(2010$, p.4) destaca, ainda, que:

[...] "em um país pobre e com tantas desigualdades sociais, um novo paradigma de desenvolvimento deve promover não só a sustentabilidade estritamente ambiental - ou seja, a sustentabilidade de espécies, ecossistemas e processos ecológicos - como também a sustentabilidade social - ou seja, deve contribuir também para a redução da pobreza e das desigualdades sociais e promover valores como justiça social e equidade. Além disso, o novo paradigma de desenvolvimento preconizado pelo socioambientalismo deve promover e valorizar a diversidade cultural e a consolidação do processo democrático no país, com ampla participação social na gestão ambiental."

Como registra a autora, o socioambientalismo passou, então, a representar uma alternativa ao conservacionismo/preservacionismo ou movimento ambientalista tradicional, mais distante dos movimentos sociais e das lutas políticas por justiça social e cético quanto à possibilidade de envolvimento das populações tradicionais na conservação da biodiversidade. Como resultado dessa luta, surge a proposta de criação 


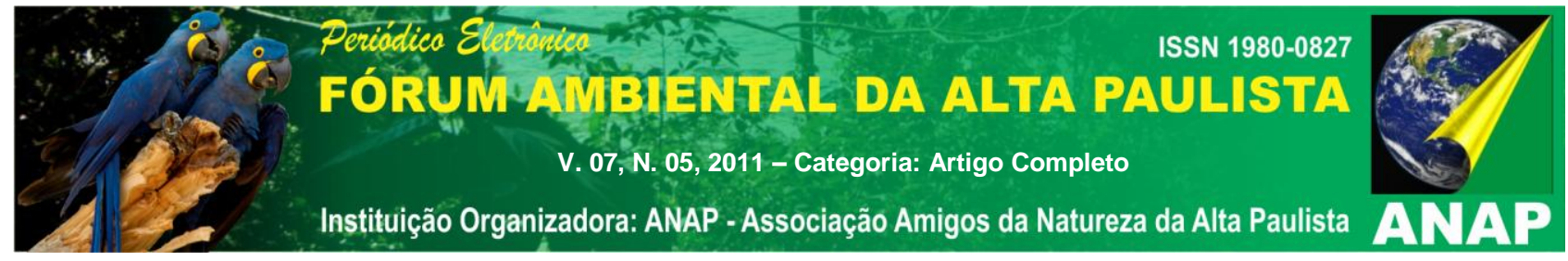

de reservas extrativistas - desenvolvida pelo movimento social dos seringueiros visando promover o casamento entre conservação ambiental e reforma agrária - que passou a ser considerada por cientistas e formuladores de políticas públicas como uma via de desenvolvimento sustentável e socialmente equitativo para a Amazônia.

A categoria "Unidades de Conservação de Uso Sustentável" é, pois, fruto de uma transformação social e ambiental, constituindo, hoje, instrumento que permite, dentro dos limites estabelecidos em lei, a utilização direta dos recursos naturais. Conforme prevê a Lei do SNUC, em seu art. $7^{\circ}$, $\S^{2} \stackrel{\circ}{ }$, seu objetivo é, justamente, compatibilizar a conservação da natureza com o uso sustentável dos recursos naturais.

De acordo com dados ${ }^{2}$ fornecidos pelo Instituto Chico Mendes de Conservação da Biodiversidade - ICMBio, órgão responsável pela gestão das unidades de conservação, criado pela Lei no 11.516, de 28 de agosto de 2007, atualmente existem 304 unidades de conservação no Brasil, sendo que 173 são UCs de Uso Sustentável, perfazendo um total de 38.835.516,35 ha e 131 são UCs de Proteção Integral, que somadas representam um total de 35.656.870,61 ha.

\begin{tabular}{|l|l|r|}
\hline \multicolumn{2}{|c|}{ Unidades de Conservação Federais do Brasil } \\
\hline Unidades de: & Categoria - Quantidade & Hectares \\
\hline Proteção Integral: PI & Esec - Estação Ecológica - 31 & $6.869 .411,18$ \\
\hline & MN - Monumento Natural - 2 & $44.179,73$ \\
\hline & Parna - Parque Nacional - 64 & $24.705 .236,36$ \\
\hline & Rebio - Reserva Biológica - 29 & $3.868 .939,47$ \\
\hline & Revis - Refúgio de Vida Silvestre - 5 & $169.103,88$ \\
\hline & & $35.656 .870,61$ \\
\hline PI Total: 131 & APA - Área de Proteção Ambiental - 31 & $9.899 .433,67$ \\
\hline Uso Sustentável: US & Arie - Área de Relevante Interesse Ecológico - 17 & $44.621,47$ \\
\hline & Flona - Floresta Nacional - 65 & $16.556 .903,48$ \\
\hline & RDS - Reserva de Desenvolvimento Sustentável & $64.441,29$ \\
\hline & -1 & \\
\hline & Resex - Reserva Extrativista - 59 & $12.270 .116,44$ \\
\hline US Total: 173 & & $38.835 .516,35$ \\
\hline Total geral: 304 & * Área Georreferenciada total & $74.492 .386,96$ \\
\hline
\end{tabular}

Com se vê na tabela acima, em termos quantitativos, há pouca diferença entre UCs de uso sustentável e UCs de proteção integral. No entanto, em termos de demandas pela execução de políticas públicas existe um grande abismo entre essas categorias, já que além da preocupação com a proteção da natureza, as UCs de uso sustentável têm o

${ }^{2}$ Disponível em: http://www.icmbio.gov.br/menu/produtos-e-servicos/download/uc federal icmbio.pdf. Acesso em 5 nov. 2010. 


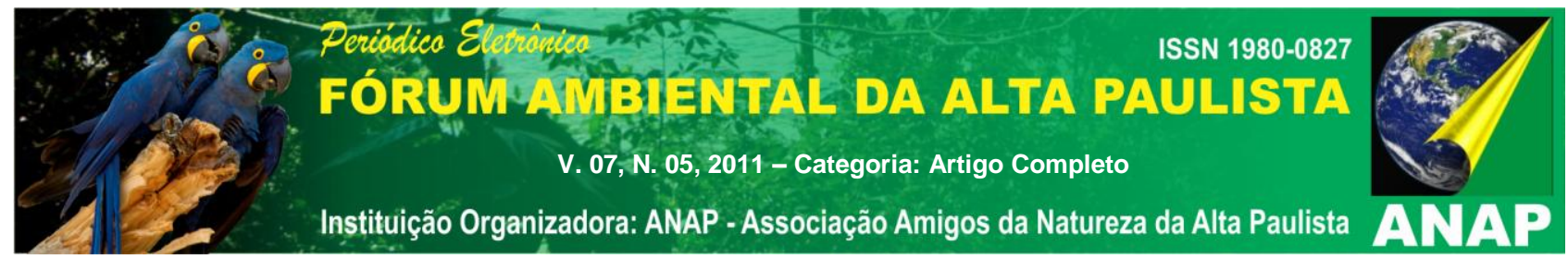

desafio de executar políticas relativas ao uso sustentável dos recursos naturais renováveis e articular políticas socioeconômicas para as populações tradicionais que nelas residem.

Para cumprir essa missão desafiadora, que é a gestão de unidades de conservação de uso sustentável, é preciso, no mínimo, de recursos humanos e financeiro, sem os quais é impossível atingir os objetivos do SNUC. Nesse aspecto, justifica-se a importância do debate ora suscitado: recursos provenientes da compensação ambiental.

\section{CONCLUSÕES}

A partir do estudo formulado, conclui-se que:

5.1 A compensação ambiental constitui mecanismo de consolidação do Sistema Nacional de Unidades de Conservação, já que permite a criação de novas UCs e a estruturação daquelas já existentes, contribuindo de forma significativa para a construção dos instrumentos de gestão, bem como para a estruturação do órgão gestor das UCs;

5.2 O SNUC beneficiou sobremaneira as UCs de Proteção Integral, no que se refere à destinação dos recursos provenientes da compensação ambiental, uma vez que o art. 36, caput, estipulou, como regra, que o empreendedor deverá apoiar a implantação e manutenção de unidade de conservação do Grupo Proteção Integral. A título de exceção (art. 36, §3º, da Lei n 9.985/00) o legislador previu que, caso o empreendimento afete unidade de conservação específica ou sua zona de amortecimento, esta deverá ser uma das beneficiárias da compensação, mesmo que não pertencente ao Grupo Proteção Integral;

5.3 Tal previsão limita a destinação dos recursos da compensação ambiental para as unidades de conservação de uso sustentável, já que jamais será criada uma UC de uso sustentável com recursos da compensação ambiental. Será possível, apenas, auxiliar na implementação, se ela for, de fato, afetada pelo empreendimento;

5.4 A distinção de tratamento das categorias de UC de Proteção Integral e Uso Sustentável quanto à destinação dos recursos provenientes da compensação ambiental é uma das consequências da forte influência da corrente preservacionista - que é contra a existência de populações tradicionais em áreas protegidas - no processo de construção 


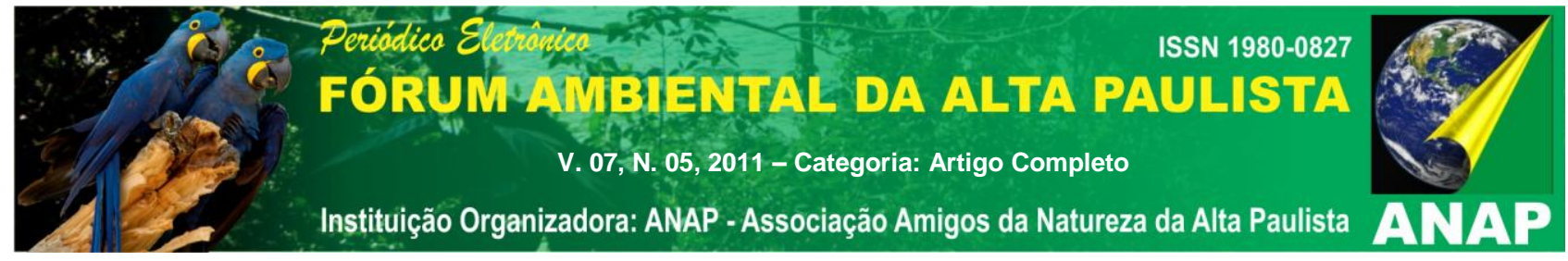

das políticas públicas ambientais.

\section{REFERÊNCIAS}

ARRUDA. Rinaldo S. V. "Populações tradicionais" e a proteção dos recursos naturais em unidades de conservação. In: DIEGUES, Antônio Carlos (org.). Etnoconservação novos rumos para a proteção da natureza nos trópicos. São Pauulo: Nupaub/USP. 2. ed.

BENSUSAN, Nurit. Conservação da Biodiversdade em áreas protegidas. Rio de Janeiro: Editora FGV, 2006, reimpressão, p. 16.

DIEGUES, Antônio Carlos Sant'ana. O mito moderno da natureza intocada. São Paulo: Nupaub/USP, 2008, p. 27 e 28.

FARIA, Ivan Dutra. Compensação ambiental: Os fundamentos e as nomas; A gestão e os conflitos. 2008. Disponível em: <http://www.senado.gov.br/senado/conleg/textos_discussao/NOVOS\%20TEXTOS/texto43 \%20-\%20lvan\%20Dutra.pdf>. Acesso em: 3 out. 2010. 9 p.

GUERRA, Sérgio. Compensação ambiental nos empreendimentos de significativo impacto. In: WERNECK, Márió et. al. Direito Ambiental visto por nós advogados. Belo Horizonte: Del Rey, 2005, p. 129.

MACHADO, Paulo Afonso Leme. Direito Ambiental Brasileiro. São Paulo: Malheiros Editores, 2006. 14ㄹ edição, p. 794.

MILANO, Miguel Serediuk. Unidade de Conservacão - Técnica, Lei e Ética paa a Conservacão da Biodiversidade. In: VIO, Antonia Pereira de Avila...et al.; coordenação, Antônio Hẻrman Benjamin. Direito Ambiental das áreas protegidas: o regime jurídico das unidades de conservação. Rio de Janeiro: Forense Universitária, 2001, p. 9.

MILARÉ, Edis e ARTIGAS, Priscila Santos. Compensaccão Ambiental: questões controvertidas. Revista de Direito Ambiental. Ano 11, no 43, julho-setembro de 2006. Coordenação: Antônio Herman V. Benjamin e Edis Milaré. Editora RT, p. 106.

MERCADANTE, Maurício. Uma década de debate e negociação: a história da elaboração da lei do SNUC. In: BENJAMIN, Antônio Herman. Dirẻito Ambiental das áreas protegidas: o regime jurídico das unidades de conservação. Rio de Janeiro: Forense Universitária, 200 \%. p. 204

PINTO, Mariana Oliveira. Estudos de impacto ambiental e unidades de conservação: algumas ponderações sobre a compensação de impactos. In: Congrȩsso Internacional de Diréito Ambiental: paisagem, natureza e Direito. São Paulo: Instituto O Direito por um Planeta Verde, 2005. vol. 2, p. 300.

SANTILLI, Juliana. A distribuicão socialmente injusta dos ônus gerados pelas criação e implantação de unidảdes de conservaçăo ambiental em áreas ocupadas por populacoes trádicionais. A viso crítica do socioambientalismo e as tentativas de superação politiccas de de tais discriminaçôes sociais através de mecanismos jurídicos criados, pela Lei do SNUC (Sistema Nacional de Unidades de Conservação da Natureza). Disponivel <http://www.anppas.org.br/encontro_anual/encontro2/GT/GT17/gt17_juliana_santilli.pdf>. Acesso em: 15 out. 2010. 